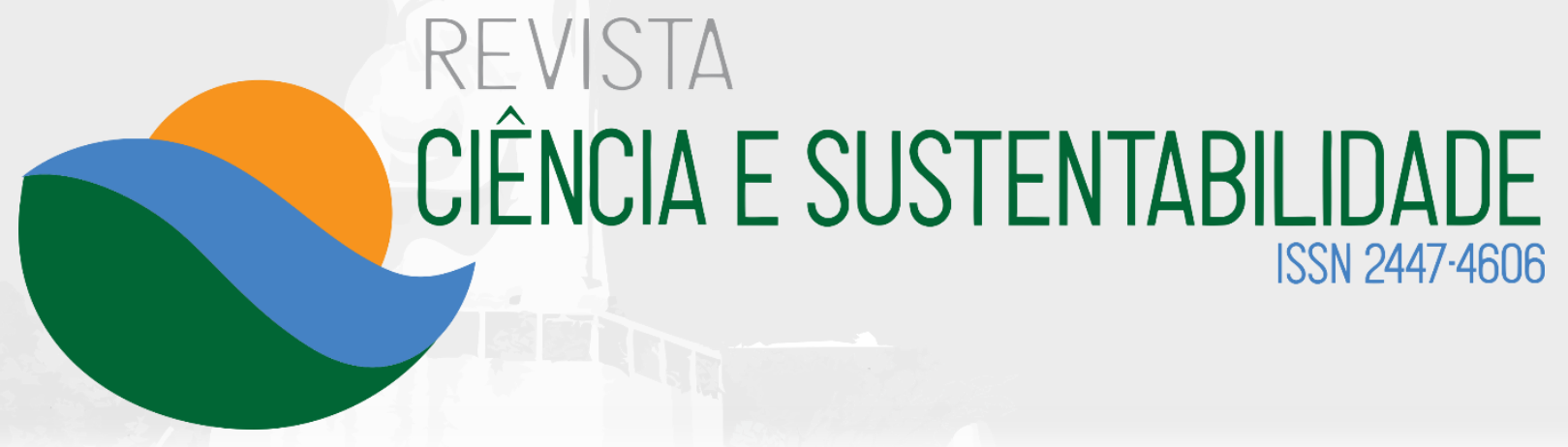

\title{
Empreendedorismo feminino: um estudo do perfil das empreendedoras do curso de administração de uma faculdade particular em Juazeiro do Norte/CE
}

\author{
Female entrepreneurship: a study of female entrepreneur's \\ profile of the administration course of a private college in \\ Juazeiro do Norte/CE
}

\section{Mila Fonteles Barbosa Ferreira Costa \\ Faculdade Paraíso do Ceará (FAP). Bacharel em Administração, Mestre em Desenvolvimento Regional Sustentável pela UFCA. \\ E-mail: mila.barbosa@fapce.edu.br}

\section{Emmanuela Suzy Medeiros}

Faculdade Paraíso do Ceará (FAP).

Bacharel em Administração, Doutora em Educação.

E-mail: emmanuela.suzy@fapce.ed.br

\section{Rebeca da Rocha Grangeiro}

Universidade Federal do Cariri (UFCA). Graduação em Psicologia pela Universidade Federal do Ceará (2002). Mestrado em Psicologia pela Universidade Federal da Bahia (2006). Doutorado em Psicologia pela Universidade Federal da Bahia (2015). Atualmente é Professora Adjunta II da Universidade Federal do Cariri.

E-mail: rebeca.grangeiro@ufca.edu.br

\section{Suelena Ferreira Oliveira}

Faculdade Paraíso do Ceará (FAP).

Bacharel em Administração. Mestre em
RESUMO

O termo empreendedorismo está sendo disseminado e estudado neste século, com ênfase no fato de não existir empregos para todos, constituindo uma saída para manutenção da atividade econômica da população. Em que o termo empreendedorismo significa mais do que uma denominação ou um conceito, trata-se de um comportamento, de uma atitude, estando associado à inovação, possibilidades de fazer coisas novas ou de maneira diferente, assim como a capacidade de assumir riscos. 0 referido trabalho apresenta um estudo de abordagem qualiquantitativa, desenvolvido através de pesquisa descritiva, bibliográfica e de campo, feita com 10 empreendedoras do curso de Administração de uma faculdade em Juazeiro do Norte/CE. Diante do exposto, o trabalho teve como objetivo geral analisar os desafios encontrados pelas empreendedoras que estudam em uma faculdade particular, no curso de administração, e como objetivos específicos compreender as faces do empreendedorismo feminino, traçar o perfil das empreendedoras, e identificar as razões que as motivaram para se tornar empreendedoras. Os resultados da pesquisa indicaram que o perfil delas é composto por mulheres jovens, que são mais propensas ao risco, solteiras e sem filhos e os motivos que levaram a abrir o empreendimento são diversos desde o desemprego, a independência financeira, a vocação e realização profissional. Diante do exposto, percebe-se que as 
Empreendedorismo feminino: um estudo do perfil das empreendedoras do curso de administração de uma faculdade particular em Jüazeiro do Norte/CE

Administração pela Universidade Federal Rural de Pernambuco (UFRPE). E-mail: suelena.oliveira@fapce.edu.br

Recebido em: 31/10/2018 I Aceito em: $12 / 02 / 2019$ mulheres estão empreendendo cada vez mais cedo, procurando tanto a satisfação profissional quanto a independência financeira, para depois pensar em constituir uma família, e os desafios enfrentados pelas mesmas são enfrentados em todos os gêneros, pois é uma questão mundial, desde a concorrência exacerbada, às crises mundiais.

Palavras-chave: Mulheres Empreendedoras. Perfil Empreendedor. Desafios para empreender.

\section{ABSTRACT}

The term entrepreneurship is being disseminated and studied in this century, with emphasis on the fact that there are no jobs for all, constituting an outlet for the maintenance of the economic activity of the population. In that the term entrepreneurship means more than a denomination or a concept, it is a behavior, an attitude, being associated with innovation, possibilities to do new things or in a different way, as well as the capacity to take risks. This study presents a qualitative and quantitative study, developed through a descriptive, bibliographical and field research, done with 10 entrepreneurs of the Administration course of a private college in Juazeiro do Norte/CE. In view of the foregoing, the main objective of the study was to analyze the challenges faced by female entrepreneurs studying in a private college, in the course of administration, and to understand the female entrepreneurs' motivated them to become entrepreneurs. The results of the survey indicated that their profile is composed of young women, who are more risk-prone, single and childless, and the reasons that led to the opening of the enterprise are diverse from unemployment, financial independence, vocation and professional achievement . In view of the above, it is noticed that women are starting to work at an earlier age, looking for both professional satisfaction and financial independence, and then think about constituting a family, and the challenges they face are faced in all genders, since it is a global issue, from exacerbated competition, to global crises.

Keywords: Entrepreneurial Women. Profile Entrepreneur. Challenges to undertake. 


\section{INTRODUÇÃO}

O empreendedorismo é uma prática que vem ganhando mais espaço no mercado devido ao crescimento econômico, principalmente por manifestar novas formas de inovação, novas tecnologias, novos postos de trabalho, apresentando uma melhora na sociedade e na qualidade de vida da população (BRITTO; WEVER, 2003).

Empreendedor é o indivíduo que faz as coisas acontecerem, antecipando-se aos fatos e com uma visão futura da organização (DORNELAS, 2014), ao ponto de transformarem o estilo de vida da sociedade, inovando, criando ou recriando coisas e comportamentos.

Apresentam características diferenciadas das demais pessoas, ou seja, os empreendedores não medem esforços para concretização de seus sonhos, procurando alternativas e aliados para tornarem seus objetivos em realidade. Além disso, estão sempre à frente dos demais gestores, principalmente por serem visionários, determinados, possuírem iniciativa, serem autoconfiantes, propensos a assumir riscos, persistentes, além de serem excelentes líderes, capazes de detectar oportunidades onde ninguém mais as vê (DEGEN, 1989; DOLABELA, 2006; DORNELAS; 2014).

É notório o crescente número de mulheres ocupando cargos de negócio, inclusive à frente de grandes empreendimentos. Esta é uma realidade observada não só no Brasil, mas mundialmente. Em vários países, políticas de incentivo à criação de empresas por mulheres, apoios na forma de subsídio e treinamento, leis de ajuda às empreendedoras, entre outras atividades, são desenvolvidas para encorajar mulheres a administrarem seu próprio negócio (MACHADO, 2002).

Observa-se que o tema tem crescido em interesse e importância para as economias regionais e para os governos, preocupados em desenvolver políticas públicas capazes de fomentar a atividade empreendedora e gerar desenvolvimento econômico. Neste contexto, percebe-se a importância de se fazer uma pesquisa que analise e verifique os traços mais marcantes do estilo de empreender dessas mulheres. Assim o referido trabalho tem como pergunta de pesquisa que norteia este estudo: qual o perfil das mulheres empreendedoras do curso de Administração? 
O trabalho teve como objetivo geral analisar os desafios encontrados pelas empreendedoras que estudam em uma faculdade particular, no curso de administração, e como objetivos específicos compreender as faces do empreendedorismo feminino, traçar o perfil das empreendedoras, e identificar as razões que as motivaram para se tornar empreendedoras.

A escolha do tema baseou-se no fato da cidade ter um grande número de empresas criadas e administradas por mulheres, além de direcionar o sujeito da pesquisa para estudantes do curso de Administração, uma vez que se trata de mulheres detentoras de certo conhecimento sobre gestão e que já escolheram 0 curso pela necessidade ou desejo de empreenderem de forma correta. Considerando a importância do empreendedorismo feminino para o desenvolvimento socioeconômico do país e tendo em vista a carência de estudos sobre o tema nas Instituições de Ensino Superior.

\section{DESENVOLVIMENTO}

As seções que seguem fazem a composição do corpo dessa pesquisa, indicando as referências bibliográficas levantadas, o estudo de campo e a análise dos dados coletados, na intenção de obter resposta aos objetivos traçados para esse trabalho.

\subsection{CONCEPÇÕES DE EMPREENDEDORISMO}

Ao abordar sobre o termo Empreendedorismo, sabe-se que é um processo pelo qual os indivíduos buscam identificar oportunidades, satisfazendo suas necessidades e desejos por meio da inovação. É uma característica que envolve iniciar algo inovador, preparar os recursos indispensáveis e assumir riscos.

Dolabela (1999a) define empreendedorismo como sendo uma ciência onde são examinados os aspectos concernentes ao empreendedor, seu perfil, suas origens, seu sistema de atividades, seu universo de atuação. 
Desde então, existem várias definições para o termo empreendedorismo. Segundo Dornelas (2018), empreendedorismo é o envolvimento de indivíduos e processos que, em conjunto, transformam ideias em oportunidades, destacando de forma geral o objetivo do empreendedorismo, que é transformar um objetivo em realidade, seja ele inovador ou não, sem medo de inventar e lançar o novo dedicando esforço, dedicação, assumindo riscos, para, enfim, desfrutar do resultado.

Conforme Hirisch e Peters (2009), o empreendedorismo pode ser apreendido como processo de criar riqueza. A riqueza é criada por pessoas que assumem os principais riscos em termos de patrimônio, tempo e/ou comprometimento com a carreira ou que fornecem valor para algum produto ou serviço. 0 produto ou serviço pode ou não ser original ou excepcional, mas o valor deve de algum modo ser lançado pelo empreendedor ao receber e localizar as habilidades e os recursos necessários.

Afirmam ainda esses autores que, apesar de existirem pessoas que demonstram características empreendedoras desde muito cedo, tornar-se empreendedor implica não apenas localizar ou identificar oportunidades de negócio, mas também agir e procurar realizá-las.

Pode-se definir o empreendedorismo como a habilidade de empreender, ou seja, tomar iniciativa, procurar soluções inovadoras e agir no sentido de achar a solução para problemas econômicos ou sociais, instigando o desenvolvimento como um todo por meio de auto realização de quem utiliza esse método de trabalho.

Entretanto o empreendedorismo expressa mais do que uma designação ou uma concepção. Trata-se de atitude, de uma conduta que caracteriza um indivíduo e sua empresa, é geralmente associado à ação, inovação e a possibilidade de assumir riscos.

\subsection{CARACTERÍSTICAS DO EMPREENDEDOR}

Ao referenciar acerca das características existentes nos empreendedores é perceptível que os mesmos apresentam traços que os vêm diferir de outros profissionais na sociedade.

Na visão de Dornelas (2014), o empreendedor é aquele que extingue a ordem econômica vigente pela introdução de novos produtos e serviços, pela criação de Ciência e Sustentabilidade - CeS. v. 4, n. 2, p. 94-114, jul./dez. 2018 
novas formas de organização ou pela exploração de novos recursos e materiais. 0 empreendedor é aquele que observa uma oportunidade e inventa um negócio para lucrar sobre ela, assumindo riscos calculados.

Por fim, é também uma pessoa que assume riscos pessoais e financeiros, reduzindo possibilidades de fracassos, fazendo o possível para colocar do seu lado as vantagens.

O empreendedor é alguém capaz de desenvolver uma visão, mas não só. Deve saber persuadir terceiros, sócios, colaboradores, investidores, convencê-los de que sua visão poderá levar todos a uma situação confortável no futuro (DOLABELA, 1999a, p. 44).

Esse empreendedor é capaz de sustentar seu ponto de vista em qualquer ocasião e possui confiança em si na busca pela realização.

Segundo Dolabela (1999a, p.45), um dos principais atributos do empreendedor "é identificar oportunidades, agarrá-las e buscar os recursos para transformá-las em negócio lucrativo". O empreendedor deve ser apto a atrair tais recursos, provando o valor do seu projeto e demonstrando que tem condições de torná-lo realidade.

Ainda de acordo com Dornelas (2008), o empreendedor possui características extras, que distinguem do seu comportamento. Possuem atributos pessoais que se somam a características sociológicas e do próprio dia-a-dia que eles acabam inovando.

O que distingue um empreendedor bem-sucedido são suas características e aptidões ditas como "personalidade empreendedora", que são o perfil característico mais habitualmente encontrado nos empreendedores de sucesso, além de terem uma adequada modelagem do negócio e um planejamento bem elaborado (BERNADI, 2010).

Diante do exposto, percebe-se que cada empreendedor tem características específicas, mas o que não foge à regra é essa vontade de fazer as coisas diferentes, desejo de inovar, o que distingue o espírito empreendedor. É aquele que sabe identificar uma oportunidade e faz dela um negócio, assumindo riscos calculados, dedicando-se profundamente, pois trabalha com prazer, gerando oportunidades e contribuindo para o desenvolvimento econômico e social do país e do mundo. 


\subsection{EMPREENDEDORISMO NO BRASIL}

Nos últimos anos o empreendedorismo no Brasil passou a ser um termo bastante discutido, especialmente no final da década de 1990. Isso ocorreu devido à preocupação com a criação de pequenas empresas que a passaram a ter que inovar para continuar no mercado. Assim, encontraram diversas alternativas para diminuir seus custos e permanecer competitivas.

Para Ferronato (2011, p. 57), "a criação de um ambiente favorável de estímulo ao empreendedorismo de menor porte, certamente, implica no desenvolvimento dos negócios no Brasil". Nessa perspectiva houve a criação de diversos mecanismos que divulgaram e consolidaram ainda mais o empreendedorismo no Brasil.

Existem muitos brasileiros que idealizam em ser empreendedores, onde possa expor suas ideias e anseios, participar de um projeto, criar, empreender. No Brasil, o número de empreendedores é relativamente alto, como também o número de mulheres empreendedoras que vem crescendo gradativamente a cada ano.

0 crescente interesse pelo empreendedorismo no Brasil vem sendo uma alternativa para a geração de empregos e para a formação de uma classe empresarial sólida, com a criação de empresas que consigam subsistir e reduzir o alto índice de falência nos negócios, comum nos países menos desenvolvidos (PAIVA JR.; CORDEIRO, 2002).

Segundo Jonathan (2016), o potencial econômico do empreendedorismo feminino brasileiro é significativo. No ambiente das micro e pequenas empresas brasileiras, é muito relevante a presença de empresas criadas e lideradas por mulheres. Mesmo lutando contra todas as adversidades, é por meio da iniciativa das mulheres empreendedoras que o mercado de trabalho se abre para um grande número de outras mulheres, diminuindo, assim, a subserviência ao poder masculino, segundo Saffioti (2013).

São vários os fatores que influenciaram nesse crescimento: importante desempenho apresentado por empresas geridas por mulheres, representatividade da força de trabalho feminino, bem como a intensificação da competitividade econômica e o constante aumento na taxa de desemprego (MACHADO, 2002). 
São dados como estes que demonstram que o empreendedorismo é de fundamental importância para o processo de desenvolvimento econômico do país, pois estimula o crescimento que reflete nas transformações econômicas e sociais da sociedade.

\subsection{EMPREENDEDORISMO FEMININO}

Nos últimos anos, o número de empreendimentos iniciados por mulheres vem aumentando de forma constante e o desenvolvimento econômico de diversos locais tem sido favorecido pela atuação das mulheres como empreendedoras (CASSOL; SILVEIRA; HOELTGEBAUM, 2007). As mulheres empreendedoras têm representado um fenômeno em crescimento em todo o mundo. Acredita-se, assim, que diante do crescente interesse da sociedade e dos governos pelo empreendedorismo feminino, também são crescentes o interesse e a curiosidade pelo tema entre os estudiosos e pesquisadores (GIMENEZ et al. 2000).

Antes economicamente dependente do marido até mesmo para definir sua identidade, hoje deseja mais do que um casamento ou a constituição de uma família. Ela busca uma identidade pessoal que inclui estilo de vida, não mais se submetendo ao que lhe é imposto, e sim buscando independência para traçar e definir seu próprio caminho, expressando sua capacidade e sua força de vontade (MACHADO, 2002).

As razões que levam muitas dessas mulheres a empreender são a auto realização e a satisfação de necessidades financeiras. A satisfação pessoal e profissional é muito relevante para as mulheres que deixam seus empregos formais buscando evolução profissional de um negócio excitante, e que realizado em um ambiente de trabalho consistente e com valores que consideram importantes (JONATHAN, 2016).

Segundo Lindo et al. (2007) as empreendedoras buscam a realização pessoal e têm preocupação constante com o negócio e com a flexibilidade de horários, assim como com os apoios emocionais e instrumentais, a qualidade de vida e o futuro do empreendimento. 


\section{BREVE HISTÓRICO SOBRE A FACULDADE PARTICULAR ESTUDADA}

A faculdade em questão tem sua localização geográfica no sul do Ceará, próxima à Bacia Sedimentar do Araripe, em região que faz fronteira com os estados do Piauí, Pernambuco e Paraíba e, ainda, sediada em um município polo comercial e religioso, favorece o recebimento de alunos de muitos municípios do Ceará e de outros estados. Hoje, a instituição tem alunos de 22 municípios.

Com um total de 2.355 alunos regularmente matriculados e o quadro de funcionários constituído por 211 profissionais, a instituição atua com competência e compromisso nas áreas de ensino, extensão e pesquisa, nos seus vários cursos.

A faculdade foi credenciada junto ao Ministério de Educação abril de 2005, com o objetivo de promover qualificação pessoal e capacitação profissional de excelência.

A instituição existe há 13 anos e se destaca na educação superior do Cariri, possuindo os cursos de Direito, Administração, Sistemas de Informação (Informática), Superior Tecnológico em Marketing, Engenharia Civil, Engenharia de Produção, Arquitetura e Urbanismo, Nutrição, Psicologia, Enfermagem e Análise e Desenvolvimento de Sistemas.

A instituição funciona numa sede própria, com todas as salas de aula amplas e refrigeradas, que contribuem para um aprendizado mais eficaz. Possui corpo docente preparado e titulado, composto em sua maioria por mestres e doutores, com tempo parcial e integral, recursos didáticos modernos e uma equipe administrativa presente, acessível e atuante, fazendo da mesma uma instituição séria, dirigida por educadores com ideal firmado na qualidade e no compromisso com o aluno.

O curso de Administração, por sua vez, tem a mesma idade da instituição, tendo sua carga horária distribuída em oito semestres letivos, contando ainda com carga horária significativa de estágio supervisionado, atividades complementares e possibilita a prática empreendedora através de uma empresa júnior, que preta consultoria para inúmeras empresas na região do Cariri cearense. 


\section{METODOLOGIA}

A pesquisa da qual resultou este artigo, conforme orienta Vergara (2017), pode ser dividida em dois grupos básicos: quanto aos fins e quanto aos meios. Com relação aos fins, a pesquisa é descritiva, por caracterizar determinada população ou fenômeno e estabelecer relações entre variáveis. Segundo Gil (2017) entre as pesquisas descritivas estão aquelas que têm por objetivo "estudar as características de um grupo", utilizando técnicas padronizadas de coleta de dados e buscando o aprofundamento das questões propostas, por meio da busca de fontes primárias no ambiente natural em que os acontecimentos ocorrem.

Quanto aos meios, foram realizadas pesquisa bibliográfica e pesquisa de campo, para o desenvolvimento deste trabalho. A pesquisa bibliográfica, segundo Gil (2017), são aquelas desenvolvidas a partir de trabalhos de pesquisas de diversos autores referente a determinado assunto. Neste contexto, foi construído referencial teórico da área em questão, a partir da pesquisa em livros, relatórios e publicações baseados em autores como Dornelas, Dolabela, Machado, entre outros que relatam acerca do empreendedorismo.

A pesquisa de campo que é descrita por Vergara (2017) como sendo uma investigação empírica, desenvolvida em locais predeterminados. Neste contexto, ela foi utilizada neste estudo considerando que os sujeitos da pesquisa foram empreendedoras que estudam no curso de administração de uma faculdade particular em Juazeiro do Norte/CE.

A pesquisa foi desenvolvida através da abordagem quali-quantitativa, sendo aplicado um questionário dividido em duas partes: a primeira parte contendo 11 perguntas fechadas sobre o perfil das respondentes contendo respostas de múltiplas escolhas, e a segunda parte contendo 14 perguntas objetivas e 1 subjetiva, sobre 0 empreendedorismo feminino, em que aplicou um pré-teste com 2 pessoas, não havendo dúvidas referente ao questionário, com as empreendedoras. Richardson (2017) considera que por meio da pesquisa há uma tentativa de se compreender detalhes dos significados e características de situações apresentadas pelos entrevistados. 
O universo da pesquisa foi composto de 10 empreendedoras estudantes de Administração de diferentes ramos. O levantamento dos dados ocorreu utilizando uma amostra não probabilística por acessibilidade. Os dados foram coletados utilizando o Google formulários e convertidos em percentagens.

\section{RESULTADOS DA PESQUISA}

A referida pesquisa entrevistou mulheres empreendedoras através de um questionário contendo duas partes, na primeira delas, identificou-se a idade das respondentes, podendo observar que a maioria, ou seja, 50\% estão entre 18 a 22 anos, $30 \%$ se encontram entre 23 a 31 anos, $20 \%$ entre os 32 a 38 , de acordo com os dados percebe-se que as empreendedoras que cursam Administração são jovens, sendo perceptível que as mesmas estão arriscando desde cedo para ter um negócio próprio, de acordo com o Gráfico 1, a seguir.

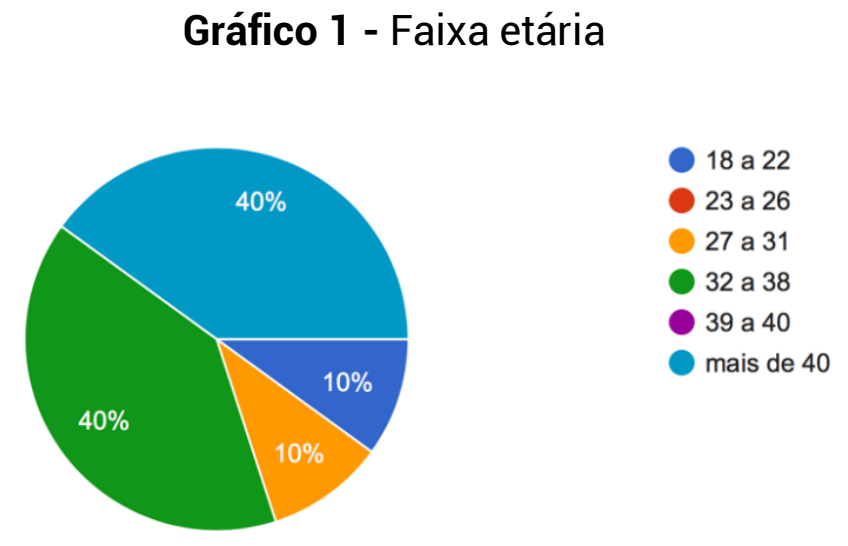

Fonte: dados da Pesquisa (2018).

Posteriormente, identificou-se o estado civil, obtendo $50 \%$ solteiras, $40 \%$ casadas e 10\% separadas, o que remete que as mulheres estão em busca de estabilidade financeira, conforme Gráficos 2. 


\section{Gráfico 2 - Estado civil}

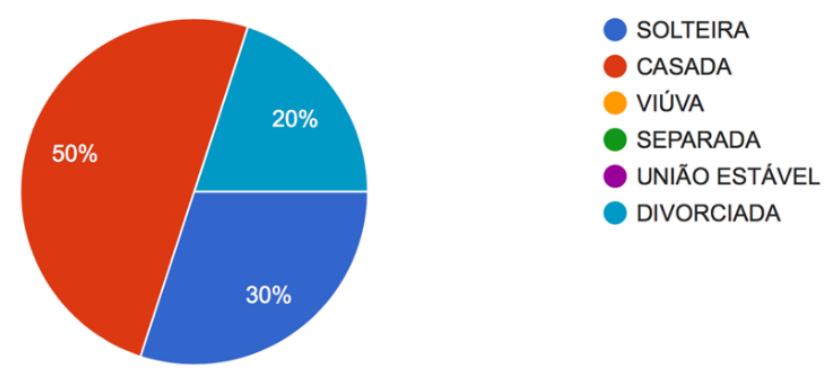

Fonte: dados da Pesquisa (2018).

Sobre o número de filhos, $100 \%$ delas não os tem. A questão referente a constituir uma família vem sendo muito debatida nos dias atuais, pois com o mundo cada vez mais competitivo, muitas mulheres abrem mão da maternidade para dar continuidade ao sucesso profissional, optando em priorizar a vida profissional.

Outro fator considerado quanto ao perfil das respondentes diz respeito ao período em que se encontram no curso de Administração, onde $50 \%$ cursam o $8^{\circ}$ semestre (último semestre do curso), $30 \%$ o $6^{\circ}$ semestre e $20 \%$ o $1^{\circ}$ semestre. É observado que há um índice considerável de mulheres empreendendo nos últimos semestres, remetendo que as mesmas possuem ou adquiriram experiências teóricas-práticas para gerir seus negócios da melhor forma possível.

Quanto à naturalidade, $50 \%$ das respondentes são naturais de Juazeiro do Norte/CE, sede da faculdade, enquanto que $20 \%$ são do Crato/CE, $10 \%$ de Milagres/CE, $10 \%$ de Caririaçu/CE e 10\% do Iguatu/CE. Levando em consideração a naturalidade de mais da maioria serem de Juazeiro do Norte e cidades circunvizinhas, percebe-se que as empreendedoras locais estão procurando cada vez mais se qualificar.

Quanto a localização da empresa, verifica-se que $70 \%$ das organizações são situadas em Juazeiro do Norte/CE, 10\% no Crato/CE, 10\% em Caririaçu/CE, 10\% em Milagres/CE. Com essa margem é perceptível que as empreendedoras, mesmo natural de outras cidades do Ceará, veem o Juazeiro do Norte/CE como uma cidade promissora para os estudos, dados descritos no Gráfico 3. 
Gráfico 3 - Localização da empresa

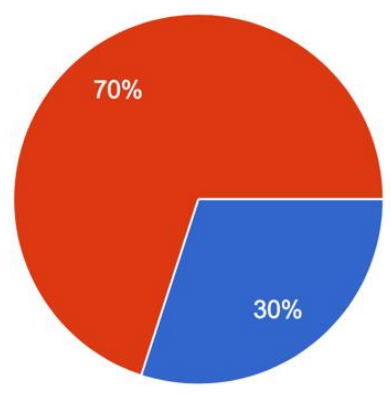

CRATO

JUAZEIRO DO NORTE CE

baRBALHA CE

MILAGRES CE

Fonte: dados da Pesquisa (2018).

Na questão referente ao tempo de empresa, $30 \%$ responderam mais de 4 anos, $30 \%$ com 2 anos, $20 \%$ um ano e $20 \%$ três anos, o que revela que mais da maioria dos empreendimentos são novos, estando ainda em fase de crescimento, experimentação organizacional, de acordo com o Gráfico 4.

Gráfico 4 - Tempo de empresa

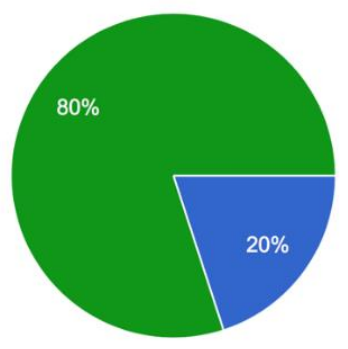

Fonte: dados da Pesquisa (2018).

Ao indagar sobre a empresa ser formalizada, $50 \%$ responderam ser informal e $50 \%$ formal, isso remete que devido ainda os altos custos de formalização e impostos cobrados pelo governo, muitas preferem viver na informalidade.

No quesito sobre a empresa ser a única fonte de renda, obteve como resposta $60 \%$ não, e $40 \%$ sim, com uma margem significativa declararam possuir outros meios de sobrevivência além da empresa, $60 \%$ declaram que a empresa funciona em casa, e $40 \%$ declararam possuir ponto fixo, destes $40 \%$ declararam ser também empresa virtual. Mostrando desse modo a nova conjuntura organizacional, que vem mudando, 
as pessoas estão unindo casa e empresa num único ambiente, além de poder gerilas de forma virtual.

Nas questões referentes ao empreendedorismo feminino observa-se que $60 \%$ possui alguém empreendedor na família, em que as mesmas relataram ser irmãos (as), pais, até a família inteira o nível de parentesco, e $40 \%$ afirmaram não possui familiares empreendedores, de acordo com o Gráfico 5. Observa-se que a presença familiar nos negócios exercer grande influência sobre o surgimento do espírito empreendedor. Quando se tem pais, irmãos entre outros empreendedores na família, as chances de se tornar empreendedor são maiores.

Gráfico 5 - Empreendedorismo na família

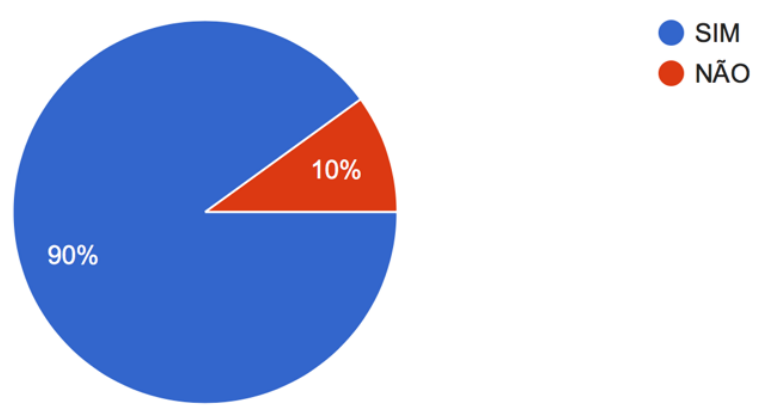

Fonte: dados da Pesquisa (2018).

Pertinente ao ramo de atividade que atua, é bem diversificado com $40 \%$ confecções, $10 \%$ clínica médica, 10\% escritório de advocacia, 10\% lanchonete, 10\% restaurante, $10 \%$ produtos eletrônicos e $10 \%$ laboratório de análise clínica, com uma margem significativa, mas que não chega a maioria, trabalhando com roupas, moda, estando os ramos bem diversificados, conforme Gráfico 6. Isto significa que as mulheres estão avançando rapidamente no mercado de trabalho, mostrando a cada dia seu excelente desempenho e contribuição no meio empresarial diversificado. 
Empreendedorismo feminino: um estudo do perfil das empreendedoras do curso de administração de uma faculdade particular em Juazeiro do Norte/CE

Gráfico 6 - Ramo de atuação

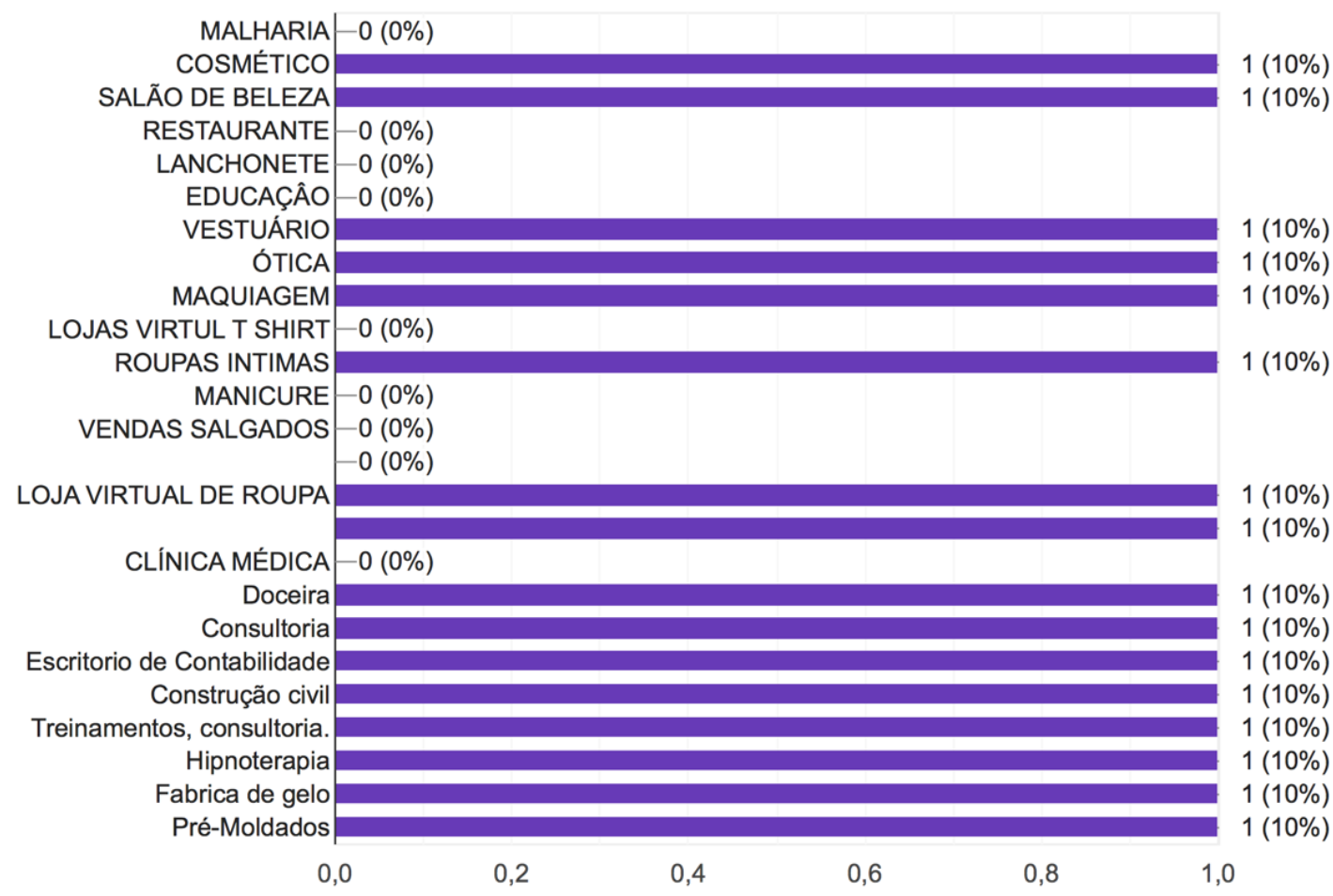

Fonte: dados da Pesquisa (2018).

No quesito referente as horas trabalhadas 60\% 8 horas por dia, 30\% 4 horas, $10 \% 6$ horas, observa-se que por estudarem no turno da noite, elas sabem dividir seus horários, se dedicando ao ensino superior.

Indagadas sobre o que motivou a abrirem seus negócios podendo assinalar mais de uma resposta, as motivações foram diversas, $80 \%$ autonomia, 40\% realização profissional, $20 \%$ flexibilidade no horário, $60 \%$ desemprego, $30 \%$ não querer ser empregada, $60 \%$ oportunidade e $50 \%$ vocação, dados percebidos através do Gráfico 7. A pesquisa veio reforçar que as mulheres estão cada vez mais buscando sua realização pessoal, serem autônomas, e optaram por empreender por que se depararam com o desemprego. Outro fator interessante é que com uma margem considerada relataram ter vocação, nasceram empreendedoras. 
Gráfico 7 - Motivação para abertura do negócio

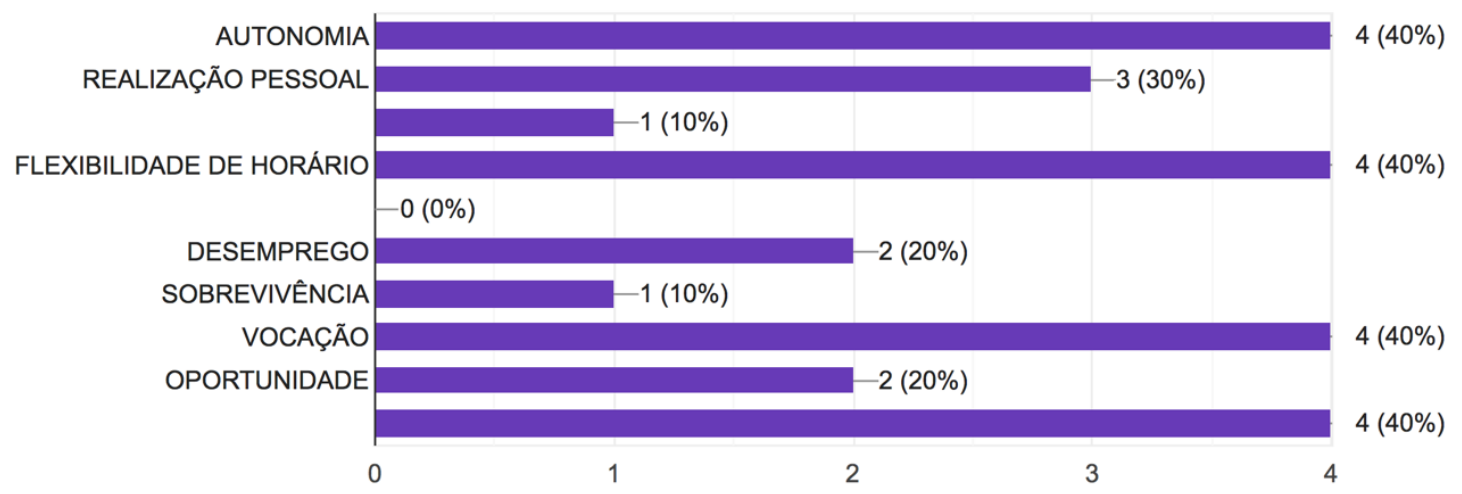

Fonte: dados da Pesquisa (2018).

Quanto à ajuda financeira, $70 \%$ responderam que tiveram ajuda financeira de familiares e bancos e $30 \%$ responderam que não, que trabalham com capital próprio. Este resultado mostra que as mulheres não tendo capital suficiente para abertura da empresa, mas o desejo de realizar o sonho foi maior que aceitaram capital de terceiros.

Com uma margem significativa de $70 \%$ relataram que após a abertura do empreendimento não recorreram a empréstimos, e 40\% necessitou para ampliar seus negócios, destes $10 \%$ afirmou ser do Banco do Nordeste.

A pesquisa mostrou que as empreendedoras estão tendo poucos momentos dedicados ao lazer, somente $40 \%$ têm momentos de lazer, $50 \%$ as vezes, $10 \%$ raramente, refletindo que mais da maioria prioriza o trabalho, que deixa para segundo plano o lazer, de acordo com o Gráfico 8.

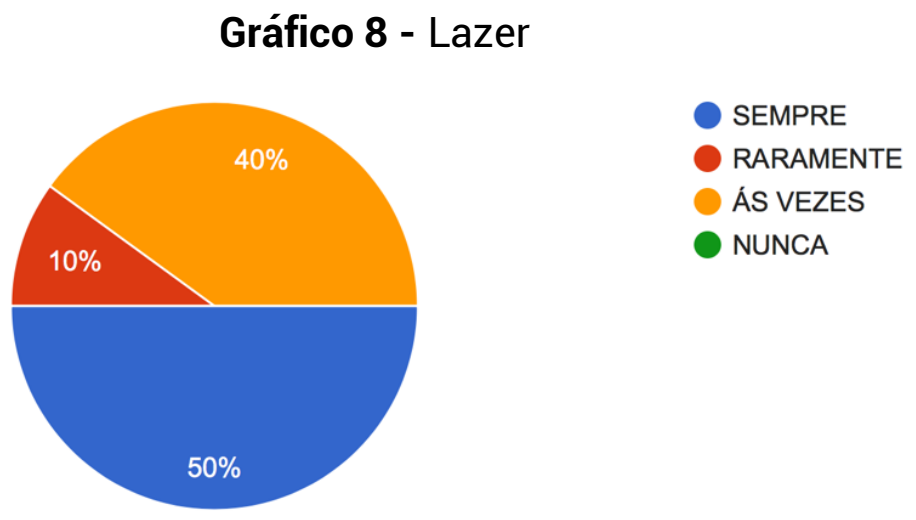

Fonte: dados da Pesquisa (2018). 
Sobre tomar decisões rápidas $80 \%$ afirmaram as vezes, $20 \%$ sempre, levando em conta que a decisão ao ser tomada as consequências virão, cedo ou tarde, positivas ou negativas, percebe-se cautela por partes das empreendedoras.

Referente a correr riscos calculados, obteve $60 \%$ as vezes, $20 \%$ sempre e $20 \%$ raramente, com uma margem considerável o índice que relata que às vezes correm riscos, remete que as mulheres empreendedoras são extremamente cautelosas, que preferem analisar tudo antes de fazer algo dentro da empresa.

No quesito desejo de inovar, $90 \%$ demonstrou sempre e $10 \%$ às vezes, com um percentual representativo que relata o desejo de inovar, sendo esta a chave para o sucesso, diversificar, superar os paradigmas para uma gestão inovadora, preparada para enfrentar a concorrência de mercado.

Ao indagar sobre autoconfiança, de acordo com o Gráfico 9, mais da maioria ou $60 \%$ respondeu sempre, $10 \%$ raramente, e $30 \%$ às vezes, partindo do pressuposto de que autoconfiança é acreditar em si no seu potencial, para que a empresa venha a crescer.

Gráfico 9 - Autoconfiança

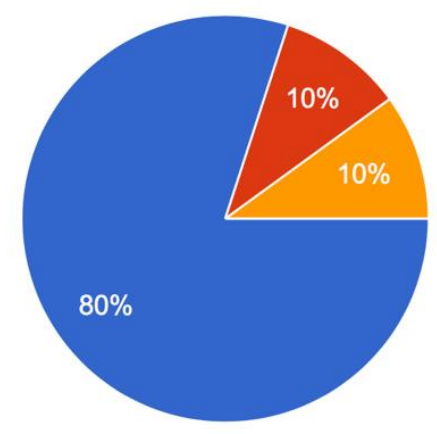

SEMPRE

RARAMENTE

ÁS VEZES

NUNCA

Fonte: dados da Pesquisa (2018).

No quesito ser paciente, e saber ouvir as pessoas obteve como resposta $60 \%$ sempre, $30 \%$ as vezes e $10 \%$ raramente. Diante disso, conforme Gráfico 10, fica evidente que as empreendedoras mostram interesse e disponibilidade para entender o que o outro quer transmitir, compartilhando as informações para um bom andamento da empresa. 
Gráfico 10 - Ser paciente e saber ouvir

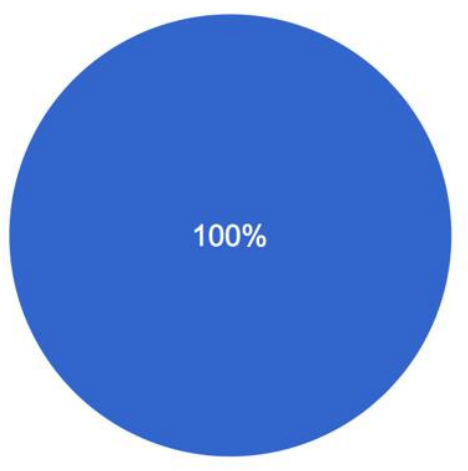

SEMPRE

RARAMENTE

ÁS VEZES

NUNCA

Fonte: dados da Pesquisa (2018).

$\mathrm{Na}$ questão aberta, sobre os desafios enfrentados por elas, enquanto empreendedoras, muitas responderam que é a economia do país e local que enfrentam crises diversas, outro ponto é a fidelização de clientes e prazos dos fornecedores, concorrência, ao analisar é verídico e sentido em todos os âmbitos pertinente a crise que passa o país, consequentemente a região do Cariri, assim como a concorrência e a fidelização pois existe inúmeras empresas similares com produtos mais baratos com a mesma funcionalidade, em que o cliente tem opção de escolher em qual empresa irá comprar, de forma física ou virtual.

\section{CONSIDERAÇÕES FINAIS}

Analisando as características do perfil das empreendedoras do curso de Administração de uma faculdade particular em Juazeiro do Norte/CE, e considerando-se a amostra do questionário analisado, o conjunto dos resultados das variáveis e fatores apresentados aponta o perfil dessas mulheres voltado para as seguintes características: tomada de decisões de maneira rápida, correr riscos calculados, mais da maioria as vezes consideraram fazer, contudo remete que as mulheres são cautelosas nas decisões, conforme a administração expõe, planejamento, organização, controle e direção, quanto a possuir desejo de inovar e visão de futuro com um percentual considerado de $90 \%$, essa resposta dada é reflexo da atual conjuntura vivenciada em meios a concorrência e as crises que as mesmas 
perpassam, e quanto a ter autoconfiança mais da maioria são empreendedoras seguras, acreditam no seu potencial. Desta forma, elas podem ser consideradas empreendedoras, pois possuem requisitos que fortalece a cada dia seu agir dentro da empresa.

Ainda com baseado nos resultados da pesquisa, conseguiu definir que o perfil apresentado pelas empreendedoras é formado em sua maioria por mulheres na faixa etária entre 18 e 26 anos, solteiras, e sem filhos, cursando os últimos períodos do curso, desse modo é perceptível que as mulheres estão empreendendo mais cedo, se preocupando com a realização profissional, deixando para segundo plano a constituição de uma família.

A pesquisa indicou, ainda, que Juazeiro do Norte/CE é um polo promissor para estudos sobre empreendedorismo e para localização dos empreendimentos, que as empreendedoras se dedicam 8 horas por dia do seu tempo às suas empresas, representando um tempo normal de trabalho, exigido pela lei para todos os colaboradores. Outro dado que pode ser relacionado a este, é que a maioria das respondentes não teve ajuda financeira de familiares para abrir o seu empreendimento, remetendo que as mesmas já possuíam alguma reserva para abrir seu empreendimento.

Percebeu-se que, dentre os fatores que motivaram as mulheres a empreenderem, realização pessoal, aumento da renda familiar, desemprego, oportunidade e vocação foram preponderantes. Outro dado interessante é que as empreendedoras veem seus empreendimentos como fonte de estabilidade financeira, e realização profissional contribuindo para a independência financeira e satisfação.

Tal dedicação, e estudos acadêmicos proporcionados pela instituição de ensino superior, pode fazer parte do tempo de abertura das organizações que as mesmas são empresas novas no mercado, estão ainda no início, mediante o exposto percebe-se que as organizações administradas pelas empreendedoras estão em fase de consolidação no mercado, levando as empreendedoras a procurarem melhorarias frequentes para não deixar seu negócio defasado.

Considerando todos esses fatores e de acordo com o a pesquisa desenvolvida e analisada, este trabalho levantou informações específicas das empreendedoras do Ciência e Sustentabilidade - CeS. v. 4, n. 2, p. 94-114, jul./dez. 2018 
curso de administração, que podem ser úteis para eventuais programas de capacitação e formação empreendedora no município, e mais investimento nesse âmbito, fato que vem sendo cada vez dinamizado pelo governo municipal, consciente da importância das organizações economia, como geradoras de emprego e renda. Espera-se que a mesma traga contribuições tanto para o meio acadêmico como para as empreendedoras que participaram do estudo.

\section{REFERÊNCIAS}

BERNARDI, Luiz Antonio. Manual de Empreendedorismo e Gestão: fundamentos, estratégias e dinâmicas. São Paulo: Atlas, 2010.

BRITO, F. WEBER, L. Empreendedores Brasileiros: vivendo e aprendendo com grandes nomes. 4. ed. Rio de janeiro: Negócio, 2003.

CASSOL, N. K.; SILVEIRA, A.; HOELTGEBAUM, M. Empreendedorismo feminino: análise da produção científica da base de dados do Institute for Scientific Information. In: ENCONTRO DA ASSOCIAÇÃO NACIONAL DE PÓS-GRADUAÇÃO E PESQUISA EM ADMINISTRAÇÃO. 31., 2007, Rio de Janeiro. Anais eletrônicos [...]. Rio de Janeiro: ANPAD, p. 1-15, 2007.

DEGEN, R. 0 empreendedor: fundamentos de iniciativa empresarial. São Paulo: McGram-Hill, 1989.

DOLABELA, Fernando. 0 segredo de Luísa: uma idéia, uma paixão e um plano de negócios: como nasce o empreendedor e se cria uma empresa. 14. ed. São Paulo: Cultura, 2006.

DOLABELA, Fernando. Oficina do empreendedor. São Paulo: Cultura, 1999a.

DORNELAS, J. C. A. Empreendedorismo na prática: mitos e verdades do empreendedor de sucesso. Rio de Janeiro: Campus, 2008.

DORNELAS, J. C. A. Empreendedorismo: transformando idéias em negócios. Rio de Janeiro: Campus, 2014.

DORNELAS, J. C. A. Empreendedorismo: transformando idéias em negócios. 7. ed. Rio de Janeiro: Empreende, 2018.

FERRONATO, Airto João. Gestão contábil-financeira de micro e pequenas empresas. São Paulo: Atlas, 2011. 
GIL, Antônio Carlos. Como elaborar projetos de pesquisa. 6. ed. Rio de Janeiro: Atlas, 2017.

GIMENEZ, F. A. P. et al. Gênero e empreendedorismo: um estudo comparativo no Paraná. In: ENCONTRO DE ESTUDOS SOBRE EMPREENDEDORISMO E GESTÃO DE PEQUENAS EMPRESAS, 1., 2000, Maringá. Anais eletrônicos [...]. Maringá:

ENANPAD, PPA/UEM-UEL, 2000.

HISRICH, R. D.; PETERS, M. Empreendedorismo. 5. ed. Porto Alegre: Bookman, 2009.

JONATHAN, E. G. Mulheres empreendedoras: desafiando estereótipos.

Departamento de Psicologia da Pontifícia Universidade Católica do Rio de Janeiro. 2006. Disponível em:

http://bancodamulher.org.br/publicações/mulheres_empreendedoras.pdf. Acesso em 15 set. 2018.

LINDO, M. R. et al. Vida pessoal e vida profissional: os desafios de equilíbrio para mulheres empreendedoras do Rio de Janeiro. RAC-e, [s.I.], jan-abr., 2007.

MACHADO, H.V. Identidade empreendedora de mulheres no Paraná. Tese (Doutorado em Engenharia de Produção). Programa de Pós-Graduação em Engenharia de Produção. Universidade Federal de Santa Catarina, 2002.

MACHADO, H.V; JANEIRO, V; MARTINS, A.B.T. Empreendedoras: estilo gerencial e desempenho das empresas. In: ENCONTRO DE ESTUDOS SOBRE EMPREENDEDORISMO E GESTÃO DE PEQUENAS EMPRESAS, Anais eletrônicos [...] [Rio de Janeiro] ENANPAD, 2003.

PAIVA JR., F. G. de; CORDEIRO, A. T. Empreendedorismo e o espírito empreendedor: uma análise da evolução dos estudos na produção acadêmica brasileira. In: ENCONTRO ANUAL DA ASSOCIAÇÃO NACIONAL DE PESQUISA E PÓS-GRADUAÇÃO EM ADMINISTRAÇÃO, 2002, Salvador. Anais eletrônicos [...]. Rio de Janeiro: ANPAD, 2002.

RICHARDSON, Roberto Jarry. Pesquisa social: étodos e técnicas. 4. ed. Rio de Janeiro: Atlas, 2017.

SAFFIOTI, H. I.B. O poder do macho. São Paulo: Moderna, 2013.

VERGARA, S. C. Projetos e relatórios de pesquisa em Administração. São Paulo: Atlas, 2017. 